\title{
Potential use of mesenchymal stem cells in human meniscal repair: current insights
}

This article was published in the following Dove Press journal:

Open Access Journal of Sports Medicine

23 March 2017

Number of times this article has been viewed

\author{
Jaewoo Pak ${ }^{1-3^{*}}$ \\ Jung Hun Lee ${ }^{1,4^{*}}$ \\ Kwang Seung Park ${ }^{4}$ \\ Jeong Ho Jeon ${ }^{4}$ \\ Sang Hee Lee ${ }^{4}$ \\ 'Stems Medical Clinic, Gangnamgu, \\ Seoul, Republic of Korea; \\ ${ }^{2}$ TEDA-Puhua International Hospital, \\ Tianjin, People's Republic of China; \\ ${ }^{3}$ Life Science Institute, Komplek \\ Permata Senayan, Jalan Tentara \\ Pelajar, Jakarta Selatan, Indonesia; \\ ${ }^{4}$ National Leading Research \\ Laboratory, Department of Biological \\ Sciences, Myongji University, Yongin, \\ Gyeonggido, Republic of Korea
}

*These authors contributed equally to this work

Correspondence: Sang Hee Lee National Leading Research Laboratory, Department of Biological Sciences, Myongji University, 116 Myongjiro, Yongin, Gyeonggido 17058, Republic of Korea

$\mathrm{Tel}+82313306195$

Fax +82 31 3358249

Email sangheelee@mju.ac.kr

\begin{abstract}
The menisci of the human knee play an important role in maintaining normal functions to provide stability and nutrition to the articular cartilage, and to absorb shock. Once injured, these important structures have very limited natural healing potential. Unfortunately, the traditional arthroscopic meniscectomy performed on these damaged menisci may predispose the joint toward early development of osteoarthritis. Although a very limited number of studies are available, mesenchymal stem cells (MSCs) have been investigated as an alternative therapeutic modality to repair human knee meniscal tears. This review summarizes the results of published applications of MSCs in human patients, which showed that the patients who received MSCs (autologous adipose tissue-derived stem cells or culture-expanded bone marrow-derived stem cells) presented symptomatic improvements, along with magnetic resonance imaging evidences of the meniscal repair.
\end{abstract}

Keywords: adipose tissue-derived stem cells, bone marrow-derived stem cells, human knee, meniscal tear, articular cartilage, therapeutic modality

\section{Introduction}

The menisci of a human knee are a pair of fibrocartilaginous structures that function to provide stability and nutrition to the articular cartilage, and to absorb shock. ${ }^{1-3}$ Removing these structures, by either full or partial meniscectomy, disrupts the homeostasis of the knee and predisposes the joint to an early development of osteoarthritis (OA) ${ }^{4-7}$

The human meniscus has very limited vascularity. The inner one-third of the meniscus (also known as the white zone due to its lack of vascularity) has lesser natural healing potential than the middle (the red-white zone, with moderate vascularity), which in turn has lesser natural healing potential than the peripheral one-third (called the red zone due to relatively abundant vascularity). ${ }^{8,9}$ Due to its lack of vascularity, symptomatic injury in the inner one-third of the meniscus may require a partial meniscectomy, even though a partial meniscectomy may result in an early development of OA of the treated knee..$^{10,11}$

As an alternative treatment to the surgical repair of meniscal tears, mesenchymal stem cells (MSCs) have been investigated. MSCs are of special interest because of their multilineage plasticity, with potential induction toward both fibrocartilage and articular cartilage. ${ }^{12,13}$ Numerous human studies have been published in the field of regenerative medicine regarding the regenerative potential of MSCs in articular cartilage. ${ }^{14-18}$ Some of these studies have demonstrated the increased volume of meniscal fibrocartilage resulting in its regeneration. ${ }^{15-17}$

For example, Centeno et al first published a case study, in which culture-expanded, autologous bone marrow-derived MSCs were administrated via a percutaneous and 
intra-articular injection into a 46-year-old male patient with a degenerative damage of a knee joint. As a result, significant meniscal cartilage regeneration was shown using magnetic resonance imaging $(\mathrm{MRI}) .{ }^{15}$

In 2011, Pak reported that two OA patients who received a percutaneous, intra-articular injection of non-expanded adipose tissue-derived stem cells (ASCs), in the form of stromal vascular fraction (SVF) with platelet-rich plasma (PRP), showed subsequent increased meniscal fibrocartilage volume, which was confirmed by MRI. ${ }^{17}$

These are two published examples of MSCs from different sources regenerating the meniscal cartilage. However, neither of these studies showed repair of meniscal tears. Because regenerating meniscal cartilage does not necessarily repair a meniscal lesion, it becomes important to look for actual cases of MSCs regenerating the torn meniscal lesions and thus improving its symptoms.

Currently, only a few human studies are available that have actually examined the effects of MSCs in potentially repairing meniscal tears in human patients. ${ }^{16,19,20}$

\section{Sources of MSCs}

MSCs can be isolated from several tissues, including bone marrow, ${ }^{21}$ synovial membrane, ${ }^{22}$ and adipose tissue. ${ }^{23}$

Bone marrow has been one of the most common sources of adult MSCs. Numerous in vitro and in vivo studies are available using bone marrow-derived stem cells. However, the number of stem cells present in fresh human bone marrow is very low ( $\sim 0.01 \%$ of the total mononucleated cells) and, therefore, the use of bone marrow requires in vitro cell expansion to obtain a sufficient quantity to be used for regenerative purposes. ${ }^{24}$ Another possible drawback of bone marrow-derived MSCs for a meniscal cartilage regeneration is that they may retain osteogenic propensities. ${ }^{25}$

Adipose tissues are another source of MSCs. Lipoaspirates can be easily obtained by liposuction. Such a tissue contains far more MSCs than the bone marrow in an identical volume. ${ }^{26}$ Due to the high number of such stem cells in adipose tissue, no cell expansion is necessary to yield regenerative effects. ${ }^{14,17,23}$ Adipose tissue-derived MSCs have been used in regenerating articular cartilage in patients with OA. ${ }^{14}$

Lastly, the synovial membrane of a knee is a potential source of MSCs. Furthermore, it has been shown that the number of MSCs in synovial fluid increases after a meniscal injury. ${ }^{27,28}$ Such autologous synovial MSCs were applied to cartilage injury. ${ }^{29}$ Currently, only one clinical study repairing chondral defect using scaffold-free three-dimensional tissue engineered construct, derived from human synovial MSCs, was completed in March 2015; but, the outcomes of the study were not reported. ${ }^{30,31}$ This may be considered to be evident that these naturally occurring MSCs may play an important role in meniscal healing and regeneration.

\section{Intra-articular delivery of MSCs}

Many modes of injecting stem cells into a human knee are available. Of those, the most attractive strategy may be percutaneous intra-articular injections of MSCs. Some of the advantages of these injections are: 1) ability to carry out the procedure in an outpatient setting, 2) minimal downtime after the procedure, and 3 ) ease of repeatability.

\section{Meniscal lesions}

Injuries to the meniscus occur in different patterns and shapes. Meniscal tear patterns can be classified as longitudinal-vertical, horizontal, radial, vertical flap, horizontal flap, and complex tears. ${ }^{32}$ Until the widespread recognition of the side effect of early development of OA in the treated knee, all these types of meniscal tears are used to be routinely resected by a total meniscectomy. However, even with partial meniscectomy, performed only when necessary to improve symptoms in injured knees, early development of OA is still a major side effect. ${ }^{33}$

With regard to the alternative repair of the meniscal tears with MSCs, it is not yet known if these different categories of meniscal tears may respond differently. It is very likely that different types of meniscal tears may require different strategies, such as different dosages of stem cells, differing periods of immobilization after stem cell injection, or possible concomitant arthroscopic resection of the tears.

\section{Applications of MSCs in repairing meniscal tears in humans}

Currently, only a few studies are available to assess the role of MSCs in repairing meniscal tears in human patients. The main features of these studies are summarized in Table 1.

In 2013, Pak et al reported a safety cohort study involving 91 patients with various joint disorders. ${ }^{20}$ A subset of 32 of these patients with degenerative and nondegenerative meniscal tears were treated with a mixture of autologous ASCs in the form of SVF, PRP, hyaluronic acid, and $\mathrm{CaCl}_{2}$. The ASCs-containing SVF was obtained by processing autologous lipoaspirates with collagenase. Then, the mixture was administrated through a percutaneous intra-articular injection into the patients with meniscal tears. The patients received additional doses of PRP with $\mathrm{CaCl}_{2}$. The study concluded that there was symptomatic improvement as measured on a visual analog scale (VAS) and a functional ratings index, along with MRI evidence of the meniscal cartilage regeneration. ${ }^{20}$ 
In 2014, a randomized, double-blind, placebo-controlled study involving 55 patients, who underwent a partial meniscectomy (resection of at least 50\%), was conducted. Patients were randomly assigned to receive allogeneic, cultureexpanded, bone marrow-derived stem cells. ${ }^{16}$ Patients were randomized into one of three treatment groups: Group A, in which patients received an intra-articular injection of $50 \times 10^{6}$ allogeneic MSCs; Group B, who received $150 \times 10^{6}$ allogeneic MSCs; and the control group, who received sodium hyaluronate as a placebo. The patients who received MSCs showed clinical improvement, assessed with the VAS and self-Lysholm knee scale, and also showed significant meniscal volume regeneration, seen on MRI at 1 year postimplantation. ${ }^{16}$

In 2014, Pak et al reported a case study in which a percutaneous intra-articular injection of autologous ASCs, in the form of SVF, along with PRP, hyaluronic acid, and $\mathrm{CaCl}_{2}$, repaired a meniscal tear in a 32-year-old female by regenerating a meniscal cartilage. ${ }^{19}$ Again, the ASCs-containing SVF was obtained by processing autologous lipoaspirates with collagenase. The mixture (ASCs-containing SVF with PRP, hyaluronic acid, and $\mathrm{CaCl}_{2}$ ) was then injected into the medial tibiofemoral joint of the patient on the same day the SVF was obtained. The patients received four additional doses of PRP with $\mathrm{CaCl}_{2}$ and hyaluronic acid on days 3, 7, 14, and 28. Afterward, a near-complete repair of the torn meniscus was seen on a repeat MRI performed at 3 months postimplantation. ${ }^{19}$

In 2016, a single-center, prospective, open-label study involving five patients with an avascular meniscal tear was conducted. ${ }^{34}$ Autologous MSCs were isolated from an iliac crest bone marrow biopsy, expanded, and seeded into the collagen scaffold. The resulting human MSC/collagen-scaffold implant was placed into the meniscal tear of five patients. The patients were followed for 24 months. All five patients treated showed significant clinical improvement on repeated measures analysis (Tegner-Lysholm score, range of motion, and the International Knee Documentation Committee [IKDC] score). Three of the five patients were asymptomatic at 24 months with clinical improvement in knee function scores and without any evidence of recurrent meniscal tear on MRI studies. Two patients required subsequent meniscectomy due to retear or nonhealing of the meniscal tear at $\sim 15$ months after implantation. No other adverse events occurred. ${ }^{34}$

\section{Discussion}

Currently, only a few successful applications of MSCs in repairing human meniscal tears have been documented. Thus, before general application of this potentially promising, minimally invasive, nonsurgical alternative, many issues (challenges and limitations) need to be resolved. First, more human studies are required, using a variety of different sources of MSCs and applying them to different categories of meniscal tears.

Second, the mechanism of how MSCs may repair meniscal tears is unclear. Some of the possible mechanisms are: 1) secretory and trophic effects of the stem cells injected ${ }^{35,36}$; 2) direct engraftment and differentiation of the stem cells introduced into the joints ${ }^{37,38}$; or 3 ) the combination of mechanisms (1) and (2). MSCs secrete a variety of cytokines, chemokines, growth factors, and exosomes..$^{39,40}$ These factors have positive effects on the growth of the surrounding progenitor cells. Furthermore, some evidence exists that the injected stem cells may actually become engrafted into the tissue and differentiate into tissue-specific cells. ${ }^{41}$

Third, the fate of MSCs injected into a joint needs to be further elucidated. According to a preclinical study, ${ }^{42}$ kneeinjected MSCs stays only in the knee joint after the injection. However, the ultimate fate of MSCs injected into a joint is not yet clear in clinical studies. MSCs may stay in the joint, attached to the lesion, and may become integrated into the target tissue, prolonging their own survival. However, some of the MSCs that are not integrated into the tissue may be removed slowly while secreting various trophic factors.

Lastly, properly designed clinical studies with valid control treatments (eg, saline) may be necessary to make an accurate conclusion regarding the effect of MSCs in regenerating meniscal cartilage. Currently, there are studies comparing PRP to MSCs to confirm the regenerative effects of MSCs. ${ }^{43,44}$ However, it is also necessary to include saline or other inert placebo therapy in a control group to establish the real regenerative effects of MSCs.

\section{Conclusion}

A comprehensive review of the literature suggests that MSCs possess an intrinsic therapeutic potential that can directly and indirectly contribute to cartilage regeneration, thus potentially healing meniscal tears and offering great potential as an alternative treatment modality. The meniscal tissue is a crucial structure that functions to provide knee stability, shock absorption, and nutrition to articular cartilages. However, once the knee is injured, the current treatment modality of meniscectomy may lead to an early development of OA in the treated knee. Thus, new treatment strategies are necessary to regenerate the damaged tissue without causing such detrimental side effects. Regenerative medicine using MSCs may offer an alternative strategy that does not result in an early development of OA in the treated knee. 


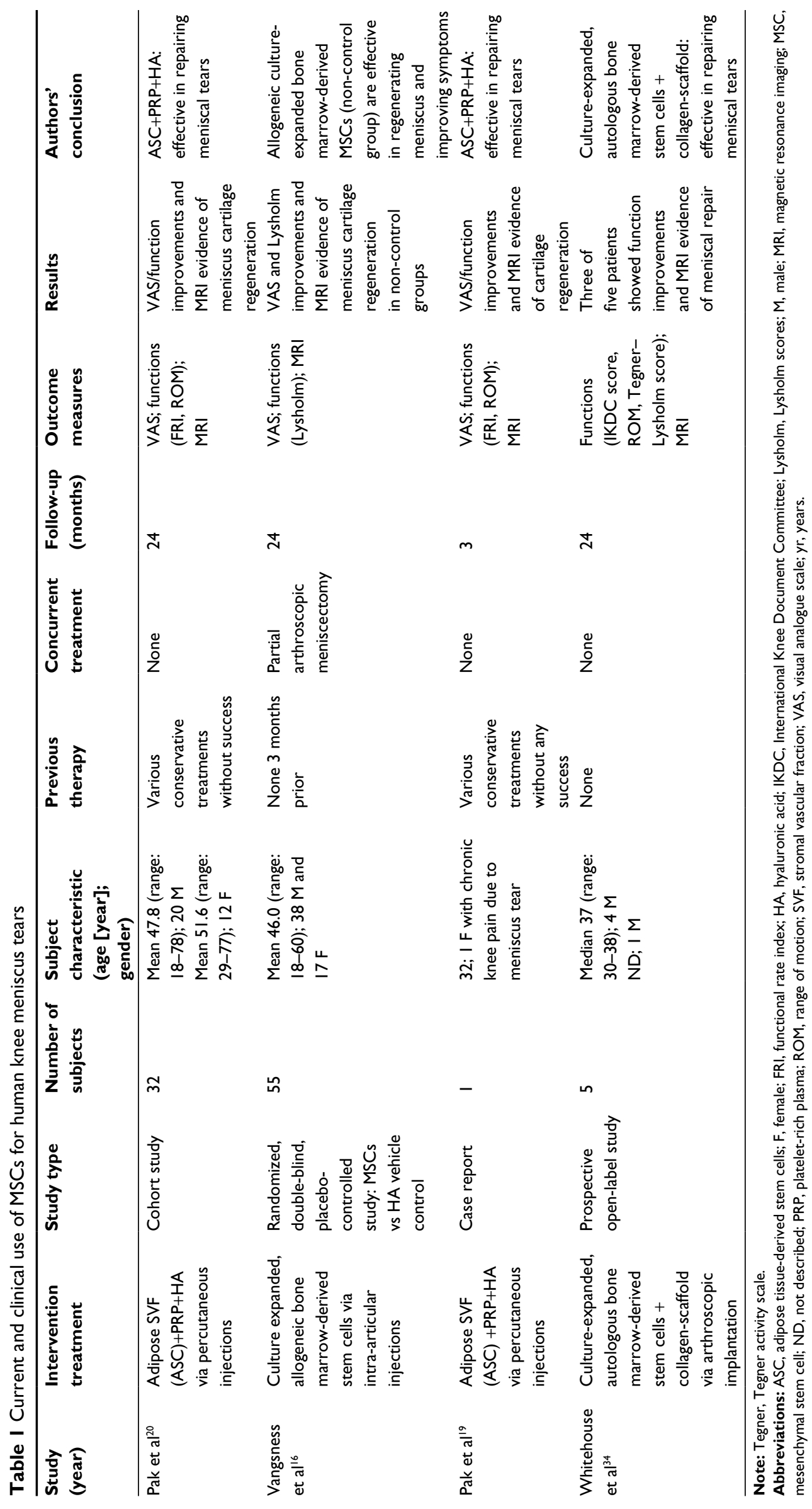




\section{Acknowledgments}

This work was supported by research grants from the National Research Foundation of Korea (NRF) funded by the Ministry of Science, ICT and Future Planning (NRF-2017R1A2B4002315 and NRF-2016R1C1B2010308), and the Cooperative Research Program for Agriculture Science and Technology Development (No. PJ01103103) of Rural Development Administration in Republic of Korea. The funding sources had no role in the writing of the report or the decision to submit it for publication.

\section{Disclosure}

The authors report no conflicts of interest in this work.

\section{References}

1. Renstrom P, Johnson RJ. Anatomy and biomechanics of the menisci. Clin Sports Med. 1990;9(3):523-538.

2. Seedhom BB, Hargreaves DJ. Transmission of the load in the knee joint with special reference to the role of menisci: part II. Experimental results, discussion and conclusions. Eng Med. 1979;8(4):220-228.

3. Ahmed AM, Burke DL. In-vitro measurement of static pressure distribution in synovial joints: part I. Tibial surface of the knee. J Biomech Eng. 1983;105(3):216-225.

4. Voloshin AS, Wosk J. Shock absorption of meniscectomized and painful knees: a comparative in vivo study. J Biomed Eng. 1983;5(2):157-161.

5. Levy IM, Torzilli PA, Gould JD, Warren RF. The effect of lateral meniscectomy on motion of the knee. J Bone Joint Surg Am. 1989;71(3):401-406.

6. Fairbank TJ. Knee joint changes after meniscectomy. J Bone Joint Surg Br. 1948;30B(4):664-670.

7. Jackson JP. Degenerative changes in the knee after meniscectomy. $\mathrm{Br}$ Med J. 1968;2(5804):525-527.

8. Arnoczky SP, Warren RF. Microvasculature of the human meniscus. Am J Sports Med. 1982;10(2):90-95.

9. Arnoczky SP, Warren RF. The microvasculature of the meniscus and its response to injury: an experimental study in the dog. Am J Sports Med. 1983;11(3):131-141.

10. Shelbourne KD, Carr DR. Meniscal repair compared with meniscectomy for bucket-handle medial meniscal tears in the anterior cruciate ligament-reconstructed knees. Am J Sports Med. 2003;31(5):718-723.

11. McGinity JB, Geuss LF, Marvin RA. Partial or total meniscectomy: a comparative analysis. J Bone Joint Surg Am. 1977;59(6):763-766.

12. Pittenger MF, Mackay AM, Beck SC, et al. Multilineage potential of adult human mesenchymal stem cells. Science. 1999;284(5411):143-147.

13. Yu H, Adesida AB, Jomha NM. Meniscus repair using mesenchymal stem cells - a comprehensive review. Stem Cell Res Ther. 2015;6(1):86.

14. Pak J, Lee JH, Kartolo WA, Lee SH. Cartilage regeneration in human with adipose tissue-derived stem cells: current status in clinical implications. Biomed Res Int. 2016;2016:4702674.

15. Centeno CJ, Busse D, Kisiday J, Keohan C, Freeman M, Karli D. Increased knee cartilage volume in degenerative joint disease using percutaneously implanted, autologous mesenchymal stem cells. Pain Physician. 2008;11(3):343-353.

16. Vangsness CT Jr, Farr J 2nd, Boyd J, Dellaero DT, Mills CR, LeRoux-Williams M. Adult human mesenchymal stem cells delivered via intra-articular injection to the knee following partial medial meniscectomy: a randomized, double-blind, controlled study. J Bone Joint Surg Am. 2014;96(2):90-98.

17. Pak J. Regeneration of human bones in hip osteonecrosis and human cartilage in knee osteoarthritis with autologous adipose tissue-derived stem cells: a case series. J Med Case Rep. 2011;5:296.

18. Wakitani S, Okabe T, Horibe S, et al. Safety of autologous bone marrowderived mesenchymal stem cell transplantation for cartilage repair in 41 patients with 45 joints followed for up to 11 years and 5 months. J Tissue Eng Regen Med. 2011;5(2):146-150.
19. Pak J, Lee JH, Lee SH. Regenerative repair of damaged meniscus with autologous adipose tissue-derived stem cells. Biomed Res Int. 2014;2014:436029.

20. Pak J, Chang JJ, Lee JH, Lee SH. Safety reporting on implantation of autologous adipose tissue-derived stem cells with platelet-rich plasma into human articular joints. BMC Musculoskelet Disord. 2013;14:337.

21. Herzog EL, Chai L, Krause DS. Plasticity of marrow-derived stem cells. Blood. 2003;102(10):3483-3493.

22. De Bari C, Dell'Accio F, Tylzanowski P, Luyten FP. Multipotent mesenchymal stem cells from adult human synovial membrane. Arthritis Rheum. 2001;44(8):1928-1942.

23. Zuk PA, Zhu M, Ashjian P, et al. Human adipose tissue is a source of multipotent stem cells. Mol Biol Cell. 2002;13(12):4279-4295.

24. Muschler GF, Nitto H, Boehm CA, Easley KA. Age- and gender-related changes in the cellularity of human bone marrow and the prevalence of osteoblastic progenitors. J Orthop Res. 2001;19(1):117-125.

25. Muraglia A, Cancedda R, Quarto R. Clonal mesenchymal progenitors from human bone marrow differentiate in vitro according to a hierarchical model. J Cell Sci. 2000;113(Pt 7):1161-1166.

26. Baer PC, Geiger H. Adipose-derived mesenchymal stromal/stem cells: tissue localization, characterization, and heterogeneity. Stem Cells Int. 2012;2012:812693.

27. Matsukura Y, Muneta T, Tsuji K, Koga H, Sekiya I. Mesenchymal stem cells in synovial fluid increase after meniscus injury. Clin Orthop Relat Res. 2014;472(5):1357-1364.

28. Matsukura Y, Muneta T, Tsuji K, Koga H, Sekiya I. Erratum to: Mesenchymal stem cells in synovial fluid increase after meniscus injury. Clin Orthop Relat Res. 2014;472(5):1357-1364.

29. Sekiya I, Muneta T, Horie M, Koga H. Arthroscopic transplantation of synovial stem cells improves clinical outcomes in knees with cartilage defects. Clin Orthop Relat Res. 2015;473(7):2316-2326.

30. Shimomura K, Ando W, Moriguchi Y, et al. Next generation mesenchymal stem cell (MSC)-based cartilage repair using scaffold-free tissue engineered constructs generated with synovial mesenchymal stem cells. Cartilage. 2015;6(2 Suppl):S13-S29.

31. Yasui Y, Ando W, Shimomura K, et al. Scaffold-free, stem cell-based cartilage repair. J Clin Orthop Trauma. 2016;7(3):157-163.

32. Wadhwa V, Omar H, Coyner K, Khazzam M, Robertson W, Chhabra A. ISAKOS classification of meniscal tears-illustration on 2D and 3D isotropic spin echo MR imaging. Eur J Radiol. 2016;85(1): 15-24.

33. Han SB, Shetty GM, Lee DH, et al. Unfavorable results of partial meniscectomy for complete posterior medial meniscus root tear with early osteoarthritis: a 5- to 8-year follow-up study. Arthroscopy. 2010;26(10):1326-1332.

34. Whitehouse MR, Howells NR, Parry MC, et al. Repair of torn avascular meniscal cartilage using undifferentiated autologous mesenchymal stem cells: from in vitro optimization to a first-in-human study. Stem Cell Transl Med. Epub 2016 Dec 15.

35. Nakagami H, Maeda K, Morishita R, et al. Novel autologous cell therapy in ischemic limb disease through growth factor secretion by cultured adipose tissue-derived stromal cells. Arterioscler Thromb Vasc Biol. 2005;25(12):2542-2547.

36. Cai L, Johnstone BH, Cook TG, et al. Suppression of hepatocyte growth factor production impairs the ability of adipose-derived stem cells to promote ischemic tissue revascularization. Stem Cells. 2007;25(12):3234-3243.

37. Mizuno K, Muneta T, Morito T, et al. Exogenous synovial stem cells adhere to defect of meniscus and differentiate into cartilage cells. $J$ Med Dent Sci. 2008;55(1):101-111.

38. Ong E, Chimutengwende-Gordon M, Khan W. Stem cell therapy for knee ligament, articular cartilage and meniscal injuries. Curr Stem Cell Res Ther. 2013;8(6):422-428.

39. Caplan AI, Dennis JE. Mesenchymal stem cells as trophic mediators. $J$ Cell Biochem. 2006;98(5):1076-1084.

40. Yeo RWY, Lai RC, Tan KH, Lim SK. Exosome: a novel and safer therapeutic refinement of mesenchymal stem cell. Exosomes Microvesicles. 2013;1(7):1-12. 
41. Ferro F, Spelat R, Falini G, et al. Adipose tissue-derived stem cell in vitro differentiation in a three-dimensional dental bud structure. Am J Pathol. 2011;178(5):2299-2310.

42. Horie M, Sekiya I, Muneta T, et al. Intra-articular Injected synovial stem cells differentiate into meniscal cells directly and promote meniscal regeneration without mobilization to distant organs in rat massive meniscal defect. Stem Cells. 2009;27(4):878-887.
43. Koh YG, Choi YJ. Infrapatellar fat pad-derived mesenchymal stem cell therapy for knee osteoarthritis. Knee. 2012;19(6):902-907.

44. Koh YG, Kwon OR, Kim YS, Choi YJ. Comparative outcomes of open-wedge high tibial osteotomy with platelet rich plasma alone or in combination with mesenchymal stem cell treatment: a prospective study. Arthroscopy. 2014;30(11):1453-1460.

\section{Publish your work in this journal}

The Open Access Journal of Sports Medicine is an international, peer-reviewed, open access journal publishing original research, reports, reviews and commentaries on all areas of sports medicine. The journal is included on PubMed. The manuscript management system is completely online and includes a very quick and fair

Submit your manuscript here: http://www.dovepress.com/open-access-journal-of-sports-medicine-journal

peer-review system. Visit http://www.dovepress.com/testimonials.php to read real quotes from published authors. 